\title{
Comprehensive genomic diagnosis of non- syndromic and syndromic hereditary hearing loss in Spanish patients
}

\author{
Rubén Cabanillas $^{1 * \dagger}$, Marta Diñeiro ${ }^{1 \dagger}$, Guadalupe A. Cifuentes ${ }^{1}$, David Castillo², Patricia C. Pruneda ${ }^{2}$,
} Rebeca Álvarez', Noelia Sánchez-Durán', Raquel Capín, Ana Plasencia³, Mónica Viejo-Díaz, Noelia García-González ${ }^{3}$, Inés Hernando ${ }^{3}$, José L. Llorente ${ }^{3}$, Alfredo Repáraz-Andrade ${ }^{4}$, Cristina Torreira-Banzas ${ }^{4}$, Jordi Rosell ${ }^{5}$, Nancy Govea ${ }^{5}$, Justo Ramón Gómez-Martínez ${ }^{3}$, Faustino Núñez-Batallaª ${ }^{3}$ José A. Garrote ${ }^{6}$, Ángel Mazón-Gutiérrez ${ }^{7}$, María Costales ${ }^{3,7}$, María Isidoro-García ${ }^{8}$, Belén García-Berrocal ${ }^{8}$, Gonzalo R. Ordóñez ${ }^{2}$ and Juan Cadiñanos ${ }^{1 *}$ (D)

\begin{abstract}
Background: Sensorineural hearing loss (SNHL) is the most common sensory impairment. Comprehensive next-generation sequencing (NGS) has become the standard for the etiological diagnosis of early-onset SNHL. However, accurate selection of target genomic regions (gene panel/exome/genome), analytical performance and variant interpretation remain relevant difficulties for its clinical implementation.
\end{abstract}

Methods: We developed a novel NGS panel with 199 genes associated with non-syndromic and/or syndromic SNHL. We evaluated the analytical sensitivity and specificity of the panel on 1624 known single nucleotide variants (SNVs) and indels on a mixture of genomic DNA from 10 previously characterized lymphoblastoid cell lines, and analyzed 50 Spanish patients with presumed hereditary SNHL not caused by GJB2/GJB6, OTOF nor MT-RNR1 mutations.

Results: The analytical sensitivity of the test to detect SNVs and indels on the DNA mixture from the cell lines was $>99.5 \%$, with a specificity > 99.9\%. The diagnostic yield on the SNHL patients was 42\% (21/50): 47.6\% (10/21) with autosomal recessive inheritance pattern (BSND, CDH23, MYO15A, STRC $[n=2], U S H 2 A[n=3], R D X, S L C 26 A 4) ; 38.1 \%$ (8/21) autosomal dominant (ACTG1 [ $\mathrm{n}=3 ; 2$ de novo], CHD7, GATA3 [de novo], MITF, P2RX2, SOX10), and 14.3\% (3/21) Xlinked (COL4A5 [de novo], POU3F4, PRPS1). 46.9\% of causative variants (15/32) were not in the databases. $28.6 \%$ of genetically diagnosed cases (6/21) had previously undetected syndromes (Barakat, Usher type 2A [n $=3]$ and Waardenburg $[n=2]) .19 \%$ of genetic diagnoses $(4 / 21)$ were attributable to large deletions/duplications (STRC deletion [ $\mathrm{n}=2$ ]; partial CDH23 duplication; RDX exon 2 deletion).

Conclusions: In the era of precision medicine, obtaining an etiologic diagnosis of SNHL is imperative. Here, we contribute to show that, with the right methodology, NGS can be transferred to the clinical practice, boosting the yield of SNHL genetic diagnosis to 50-60\% (including GJB2/GJB6 alterations), improving diagnostic/prognostic accuracy, refining genetic and reproductive counseling and revealing clinically relevant undiagnosed syndromes.

Keywords: Hereditary, Hearing loss, Precision, Diagnostics, NGS, Gene panel

\footnotetext{
* Correspondence: rcabanillas@imoma.es; jcb@imoma.es

${ }^{\dagger}$ Rubén Cabanillas and Marta Diñeiro contributed equally to this work.

${ }^{1}$ Instituto de Medicina Oncológica y Molecular de Asturias (IMOMA) S. A,

Avda. Richard Grandío s/n, 33193 Oviedo, Spain

Full list of author information is available at the end of the article
}

(c) The Author(s). 2018 Open Access This article is distributed under the terms of the Creative Commons Attribution 4.0 International License (http://creativecommons.org/licenses/by/4.0/), which permits unrestricted use, distribution, and reproduction in any medium, provided you give appropriate credit to the original author(s) and the source, provide a link to the Creative Commons license, and indicate if changes were made. The Creative Commons Public Domain Dedication waiver (http://creativecommons.org/publicdomain/zero/1.0/) applies to the data made available in this article, unless otherwise stated. 


\section{Background}

Congenital profound deafness affects $\sim 1$ in 1000 live births and an additional 1 in 1000 children will suffer from hearing loss (HL) before becoming adult [1]. Up to $60 \%$ of congenital/early-onset sensorineural HL (SNHL) is caused by genetic factors and often appears in the absence of a family history for deafness. Although alterations in the GJB2 and GJB6 genes (DNFB1 locus) account for a large proportion of cases in different populations (10$40 \%)[2,3]$, many cases remain undiagnosed after GJB2/GJB6 testing. This is not surprising given the extreme genetic and phenotypic heterogeneity of $\mathrm{HL}$, with more than 400 syndromes that include $\mathrm{HL}$ as a feature and more than 100 genes associated with nonsyndromic SNHL [1]. With next-generation sequencing (NGS) technology, it has become feasible and affordable to routinely sequence a large number of genes per patient [4]. Therefore, genetic diagnosis of SNHL has evolved from single-mutation Sanger sequencing to comprehensive multi-gene testing, and NGS has become the new standard of care [5].

Accordingly, once a case of newborn SNHL is confirmed, testing for congenital cytomegalovirus infection and NGS are recommended [6]. Obtaining a SNHL genetic diagnosis has a number of advantages for patients and parents [7]: it provides information about genetic heritability; it helps diagnosing or excluding syndromic causes of HL to better define medical and educational needs; it can also provide information about the evolution of the HL and/ or of its associated syndromic features, improving prognostic accuracy; and it can prevent other unnecessary and costly testing [5]. Furthermore, a genetic diagnosis can contribute to prevent triggers such as aminoglycosides in mitochondrial mutation carriers [8], or even to improve treatment selection, including future mutation-driven clinical trials $[9,10]$.

In order to implement targeted NGS into the clinical practice, there is an urgent need to solve a number of issues such as the selection of the most efficient gene panel, the achievement of high analytical specificity and sensitivity, and the establishment of pipelines able to unambiguously define the clinical impact of genetic variants [11]. Therefore, the aims of this study are: (1) to present the development and validation of a NGS-based approach for the genetic diagnosis of patients with hereditary syndromic and non-syndromic SNHL; (2) to pinpoint and resolve the main problems associated with the introduction of targeted NGS into routine deafness diagnostics; (3) to evaluate the panel's performance and diagnostic yield; and (4) to initiate a comprehensive catalogue of the Spanish genome-wide SNHL variation spectrum.

\section{Methods}

\section{Purpose of test}

The aim of the performed test $\left(\mathrm{OTOgenics}^{\mathrm{TM}}\right)$ was to detect the molecular basis of individual clinical diagnoses of sensorineural or mixed hearing loss after non-genetic causes had been explored and not identified.

\section{Design of panel content: Rationale for inclusion of specific genes}

Genes associated with prelingual, postlingual and adult-onset sensorineural or mixed HL, either symmetric or asymmetric, irrespective of the pattern of inheritance, and including both syndromic and non-syndromic forms, were considered. To generate a preliminary gene list, the professional version of the Human Gene Mutation Database (HGMD) was queried to identify genes associated to HL, using as search keywords a list of phenotypes potentially related to hearing defects (Additional file 1). The resulting gene list was manually curated by analysis of the literature and information available in the databases (HGMD, OMIM, PubMed, GeneReviews, and the Hereditary Hearing Loss Homepage; last accessed 19/09/2017) to identify those fulfilling the following criteria: I) the gene had been associated to sensorineural and/or mixed HL phenotypes (as opposed to exclusively conductive HL), II) there existed published evidence supporting the gene-phenotype association in at least two independent families and III) at least one of the existing publications demonstrated convincing cosegregation of phenotype with gene variants. Based on the curation results, a tiered classification system was devised as previously proposed by Abou Tayoun et al. [11]. Genes with strong/moderate association with HL (fulfilling criteria I, II and III described above, and corresponding mainly to Evidence level 3 according to Abou Tayoun et al. [11]) formed tier 1, while genes with weak/preliminary association (fulfilling criterion I, but not criteria II and/or III, and corresponding mainly to Evidence level 2 according to Abou Tayoun et al. [11]) were grouped in tier 2 . The panel evolved with revision of newly published literature, yielding versions v1, v2 and v3 (Additional file 2, Additional file 3 and Table 1, respectively). v1-2 were used during the research and development phase of the study, whereas v3 was considered the first clinical-grade version of the panel. 32 cases were analyzed with v1, 13 with v2 and 5 with v3 (Additional file 4).

\section{Sample types}

$4 \mathrm{ml}$ of peripheral blood in conventional EDTA-tubes or $\geq 200$ ng of germline genomic DNA (quantitated by a fluorimetric method) were required per patient.

\section{Sample preparation and evaluation of genomic DNA integrity}

Germline genomic DNA was isolated as previously described [12] and calculation of its DNA integrity number (DIN) was performed using the Genomic DNA ScreenTape Assay on a TapeStation 4200 system (Agilent Technologies, 


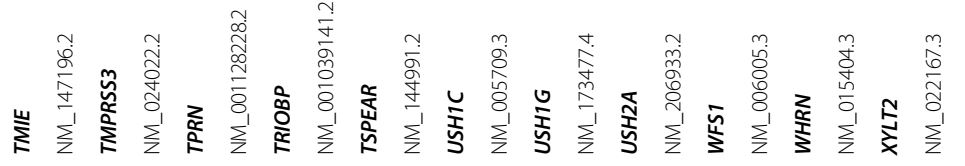

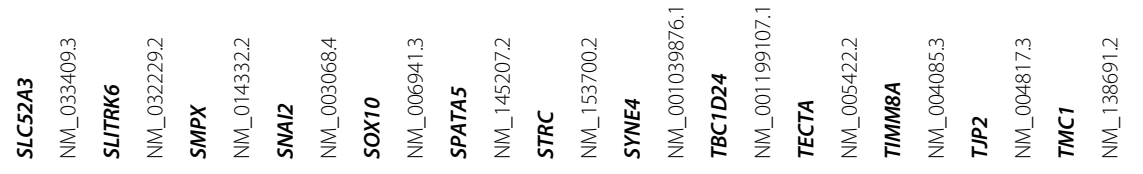

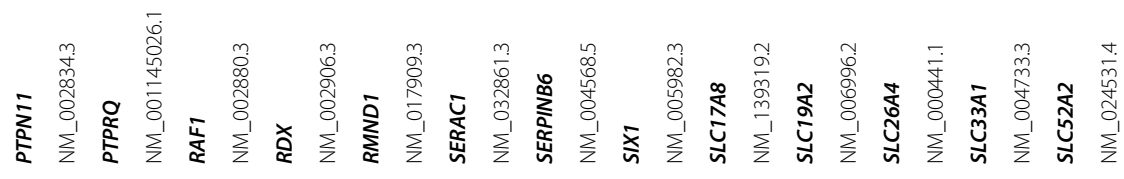

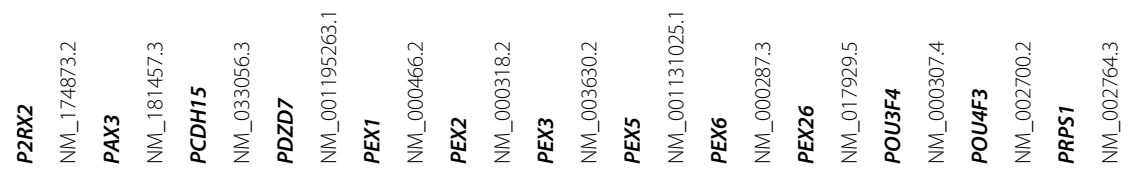

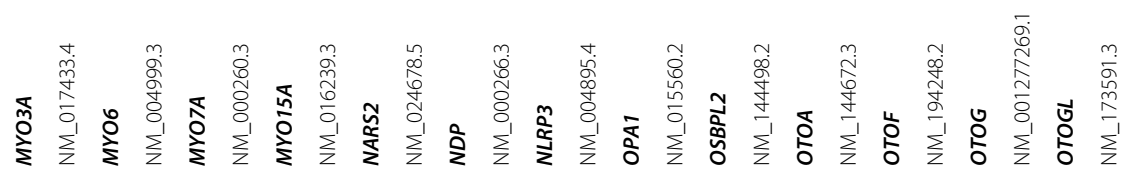

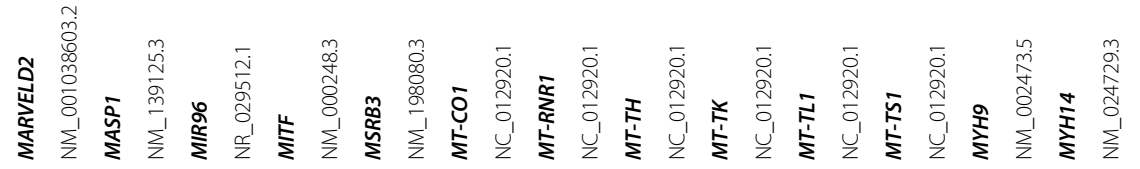

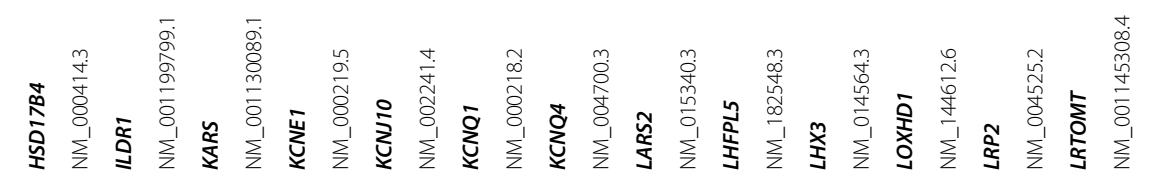

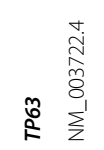

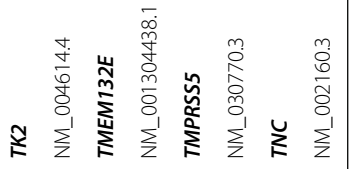

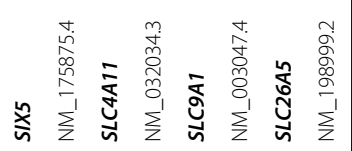

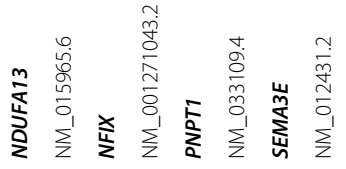

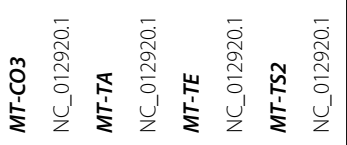

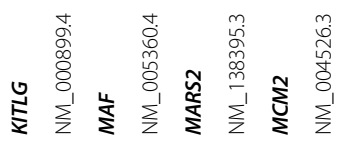

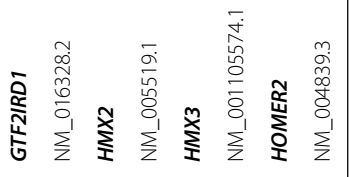

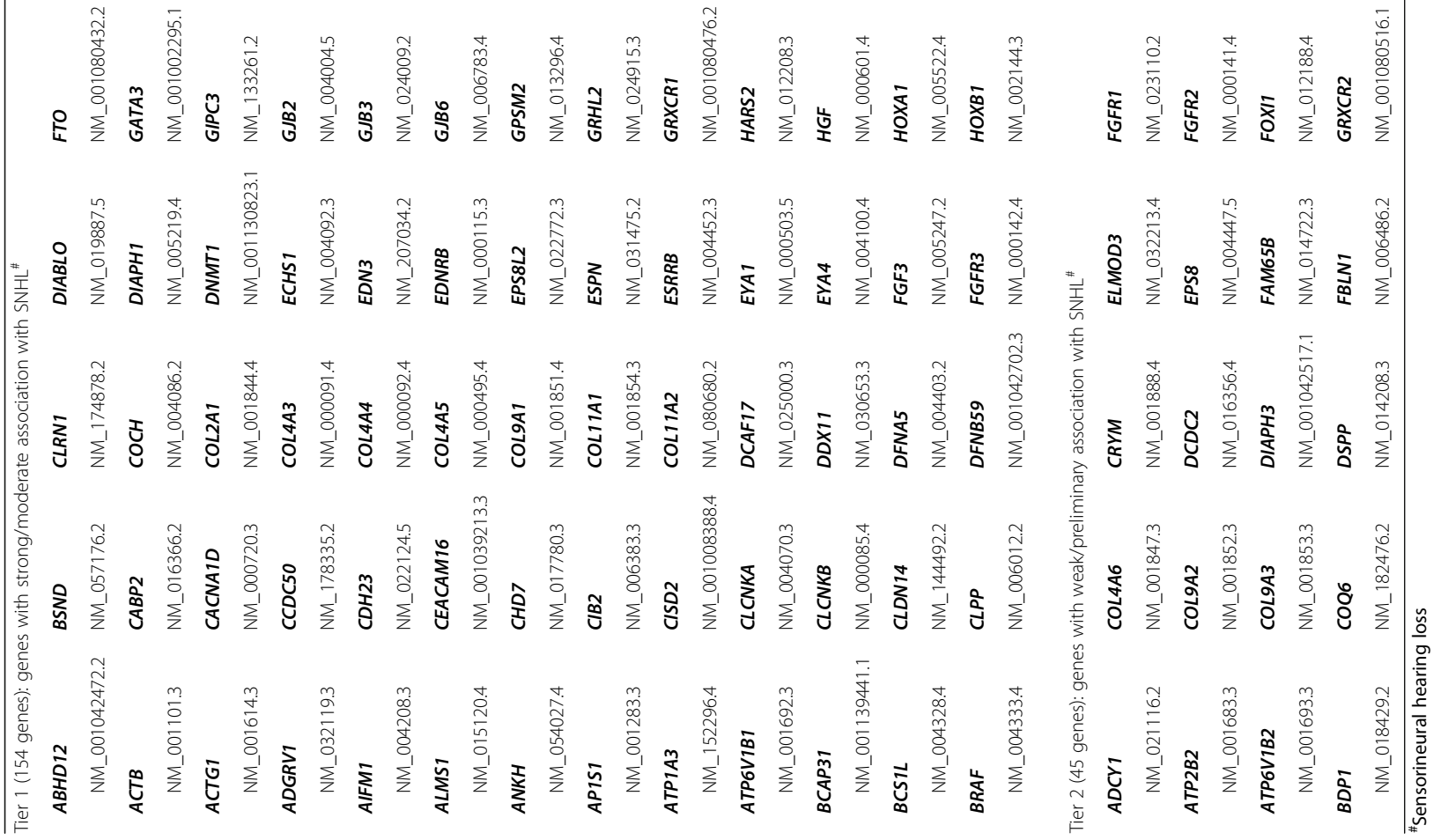


Santa Clara, CA, USA), following the manufacturer's instructions.

\section{Library preparation, target enrichment and sequencing} Library preparation was performed on genomic DNA physically sheared by ultrasonication on a Covaris S2 instrument (Covaris, MA, USA). For library construction and gene target enrichment by hybrid capture, the SureSelectXT protocol was followed, as previously described [12]. This approach has a series of advantages over other library construction and target enrichment methods. Thus, libraries from randomly fragmented DNA show higher complexities than PCR-based ones, enabling the identification and removal of PCR duplicates (important for the accurate identification of low frequency variants present in mosaic patients) [13]. Additionally, capture probes, although laborious to use, are more tolerant to mismatches than PCR primers, circumventing issues of allelic dropout (underrepresentation or absence of an existing allele in the library) caused by polymorphisms in the hybridization sequence that can be observed in amplification-based assays [13]. Finally, capturing and sequencing at least all coding exons of every targeted gene, and not just hotspots, facilitates creating background references for CNV calling. Sequencing was performed on a NextSeq500 sequencer (Illumina, CA, USA), following the manufacturers specifications. The optimized NGS diagnostic pipeline (OTOgenics ${ }^{\text {TM }}$ ) targets the coding exons and intron-exon junctions of 199 genes (v3) (Table 1).

\section{Bioinformatics for variant identification and annotation}

NGS results were processed using the bioinformatics software HD Genome One (DREAMgenics, Oviedo, Spain), certified with IVD/CE-marking. The pipeline has been adapted from the one previously described as part of the ONCOgenics NGS platform [12], the performance of which has been externally evaluated through participation in the Oncogene Panel Testing schemes organized by the European Molecular Genetics Quality Network (EMQN), obtaining satisfactory results (maximum genotyping score) for three consecutive years $(2015,2016$ and 2017). The analysis workflow was at follows:

FASTQ read generation, alignment and duplicate removal FASTQ reads were generated from base call files (BCL) produced by the Illumina NextSeq500 sequencing platform using the bcl2fastq2 v2.19 Conversion Software (https:// support.illumina.com/sequencing/sequencing_software/ bcl2fastq-conversion-software.html). Raw FASTQ files were evaluated using quality control checks from FastQC (http:// www.bioinformatics.babraham.ac.uk/projects/fastqc/) and Trimmomatic was employed to remove low quality bases, adapters and other technical sequences. Each FASTQ file was aligned to the human reference genome (GRCh37/ hg19 before 2017; GRCh38/hg38 afterwards) using BWAmem [14] generating sorted BAM files with SAMtools [15]. Reads from the same libraries were then merged and optical and PCR duplicates were removed using Picard (http://broadinstitute.github.io/picard/).

\section{SNV/Indel identification}

SNVs and indels were identified using a variation of Sidrón algorithm, previously described [16], with the following parameters: total read depth $\geq 6$, mutated allele count $\geq 3$, variant frequency $\geq 0.1$, base quality $\geq 20$, mapping quality $\geq 30$. Stricter criteria (total read depth $\geq 10$, mutated allele count $\geq 4$ ) were applied before the selection of reportable variants. Manual inspection was then carried out to discard false positives and avoid missing true variants not meeting those criteria (i.e long indels with underestimated frequencies).

\section{CNV identification}

The detection of CNVs was performed with an adapted version of the exome2cnv algorithm, incorporating a combination of read depth and allelic imbalance computations for copy number assessment. The algorithm employs a background of pooled samples processed using the same capturing protocol and sequencing technology [12, 17]. For increased sensitivity in the detection of large homozygous deletions, genomic regions with no sequencing coverage in an individual sample, but showing proper coverages in the remaining samples, were identified.

\section{Variant annotation}

Variants were annotated using several databases containing functional (Ensembl, CCDS, RefSeq, Pfam), populational (dbSNP, 1000 Genomes, ESP6500, ExAC) and disease-related (Clinvar, HGMD professional) information, as well as 12 scores from algorithms for prediction of the impact caused by nonsynonymous variants on the structure and function of the protein (SIFT [18], PolyPhen2 [19], PROVEAN [20], Mutation Assessor [21], Mutation Taster [22], LRT [23], MetaLR, MetaSVM [24], FATHMM, FATHMM-MKL [25] and M-CAP [26]), and 1 score $(\mathrm{GERP}++)$ for evolutionary conservation of the affected nucleotide [27].

\section{Analytical sensitivity and specificity}

The analytical sensitivity and specificity of our panel to detect SNVs/indels was calculated using the v3 probe set to evaluate 1624 total variants (1503 SNVs + 121 indels) with allelic frequency $\geq 0.1$, following a procedure similar to that previously described [12]. Briefly, 10 immortal lymphoblastoid cell lines, corresponding to 10 individuals whose genomes/exomes had been sequenced by the 1000 Genomes and HapMap projects, were obtained from the Coriell Institute: NA20298 (ASW), NA12872 (CEU), NA18570 (CHB), HG00320 (FIN), HG00110 (GBR), A18960 (JPT), NA19020 
(LWK), NA19794 (MXL), HG00740 (PUR) and NA18486 (YRI). Cell lines were cultured according to the protocols provided by Coriell, their DNAs isolated and mixed in equimolecular amounts. An NGS library was prepared, captured using the custom probe and sequenced in $20 \%$ of a NextSeq500 MidOutput run $(2 \times 75$ sequencing cycles $)$. Variants were called as described in the previous section and the results compared to those expected according to the genomic information available for these cell lines.

\section{Interfering highly homologous regions}

Regions with $<100 \%$ callability at DP20 (i.e. with less than $100 \%$ of the target bases covered by $\geq 20$ reads) in $>50 \%$ of v3 cases were considered as potential conflictive regions (Additional file 5). Those showing high homology to at least another region of the GRCh38 human reference genome are listed in Additional file 6. Realignment of the NGS results with reference sequences containing only the panel genes affected by these conflictive regions was performed, as previously described for the PMS2 gene [12], followed by validation, using gene-specific analyses (i.e. Long-Range PCR followed by Sanger sequencing) of putative pathogenic/likely pathogenic SNV and indel variants [28].

\section{Variant filtering, interpretation, classification and diagnostic yield}

Database resources to evaluate gene variants included HGMD professional, OMIM, PubMed, dbSNP, 1000 Genomes Project, ESP, ExAC, and ClinVar. A minor allele frequency (MAF) cut-off of 5\% was applied to variants considered as pathogenic (DM) by HGMD or as pathogenic/likely pathogenic by ClinVar, as well as to those variants predicted to create a null allele (nonsense, frameshift causing premature STOP codons, canonical splicing-site disruption, ATG-loss and complete exon deletions/duplications). A MAF cut-off of $1 \%$, as suggested by Shearer et al. [29], was applied to all other variants predicted to affect the sequence/expression of the protein (for protein-coding genes) or of the RNA (for non-coding genes).

Clinical classification of all variants from v1 and v2 cases was performed as described [12]. For v3 cases, only variants that could potentially explain the SNHL phenotype of the probands, based on zygosity of the variant, presence of additional variants on the same gene and mode of inheritance of the audiologic phenotypes associated to the gene, were further considered. After that, variants were clinically classified according to the American College of Medical Genetics and Genomics (ACMG) guidelines as pathogenic (class 5), likely pathogenic (class 4 ), uncertain significance (class 3 ), likely benign (class 2 ) and benign (class 1) [30]. Class 3-5 variants were thoroughly curated searching the literature and databases for clinically relevant data. Class $3-5$ variants were reported for tier 1 genes. To reduce the interpretation burden of tier 2 genes, only class $4-5$ variants affecting genes whose associated putative phenotype matched the patient's phenotype were evaluated and reported.

Diagnostic yield (generally described as the likelihood that a test or procedure will provide the information needed to establish a diagnosis) was defined as the percentage of tested patients with pathogenic/likely pathogenic variants capable of explaining their HL phenotype.

\section{Variant validation}

Pathogenic/likely pathogenic variants considered responsible for SNHL were validated by approaches alternative to NGS. SNVs/indels were validated by PCR + Sanger sequencing. For validation and breakpoint identification of the partial $C D H 23$ duplication (exons 11-15) and the $R D X$ exon 2 deletion multiple PCR reactions were performed. STRC $\mathrm{CNVs}$ were validated with a qPCR assay able to distinguish STRC from the $p S T R C$ pseudogene [28] as well as by MLPA (MRC-Holland, Amsterdam, The Netherlands; cat.\# P64-DIS). Primers used in validation PCRs are described in Additional file 7). Segregation was determined in $8 / 8$ $(100 \%)$ relatives with available biospecimens.

\section{Reportable range}

Reportable variants had to be supported by $\geq 4$ independent reads, with a total read depth $\geq 10$, belonging to genes from Tier 1 (consistently associated) and showing allelic frequencies in the sample $\geq 0.1$. Variants considered responsible or likely responsible for the phenotype of the patient additionally needed to have been validated by a method alternative to NGS to be considered reportable. Occasionally, a variant from a Tier 2 gene fulfilling all other criteria could be reportable, as long as the phenotype of the patient was compatible with the phenotype considered in the existing publications supporting the gene-phenotype association of the Tier 2 gene.

\section{Reference range}

Only variants consistent with the mode of inheritance of the auditory phenotypes associated with the gene they affect (for instance, biallelic variants on a gene with a recessive phenotype) were evaluated according to ACMG/AMP guidelines and their resulting clinical classification was reported [30]. For those classified as pathogenic, likely pathogenic or VUS, additional information supporting their clinical classification was provided. Those classified as benign or likely benign were considered to lay within the reference range of results and, thus, no further details about them were provided. The remaining variants (not consistent with the mode of inheritance of the auditory phenotypes associated with the genes they affect) were included in the reports for informative purposes but were not considered responsible for the patient's phenotype. 


\section{Sample tracking}

A series of 6 SNPs on Tier 1 genes, with population MAFs between 0.463 and 0.483 , were selected for sample tracking: rs10864198 on USH2A (MAF $=0.4531$; ExAC); rs7598901 on ALMS1 (MAF = 0.4736, 1000 Genomes); rs2228557 on COL4A4 (MAF $=0.4657 ;$ ExAC), rs7624750 on OPA1 $(\mathrm{MAF}=0.4683$; ExAC), rs734312 on WFS1 $(\mathrm{MAF}=0.4633$; ExAC), and rs2438349 on ADGRV1 (MAF = 0.4830; ExAC). The genotypes identified by the NGS pipeline were compared to those obtained from the corresponding TaqMan qPCR genotyping assays (cat \#: C_31803731_10, C_29307975_10, C_11523965_10, C_ 2715859_10, C__2401729_1 and C_16236492_10, respectively; Applied Biosystems, CA, USA) run on a 7900HT Fast Real-Time PCR System (Applied Biosystems, CA, USA). All samples showed coincident genotypes for all SNPs on both platforms.

\section{Patient population}

Between September 2014 and March 2017, 50 consecutive patients (21 male, 29 female) with syndromic/non-syndromic SNHL were selected after excluding non-genetic causes and causative variants in the DFNB1 (GJB2/GJB6), $O T O F$ and MT-RNR1 loci, considered the most frequent causes of hereditary deafness in Spain [7,31]. Consent was obtained from patients or their parents. The study was approved by the Comité de Ética de Investigación del Principado de Asturias (research project \#75/14). The ages at SNHL onset ranged between 0 to 47 years (median: 12 years). 20 cases (40\%) were congenital. To identify syndromic SNHL, a clinical geneticist evaluated the patients. 2/50 patients were diagnosed (pre-test) of Alport and CHARGE syndromes. Other 3 patients presented with potentially syndromic complications, without fulfilling criteria for known syndromes.

\section{Results \\ Panel validation \\ Performance of targeted NGS}

Mean coverage of tier 1 genes was $445 \times$ for v1, $515 \times$ for v2 and $1121 \times$ for v3, and 98.87, 99.56 and $99.95 \%$ of their target bases were covered by 20 or more reads, respectively (these calculations exclude the STRC and OTOA genes due to their high homology to other genomic regions). The minimum, average and maximum coverage (average read depth of all target bases of the gene) and callabilities (\% of the target bases of the gene with minimum read depths of $10,20,50$ and 100 reads per each target base of the gene) for every tier 1 and tier 2 gene on samples analysed with OTOgenics v3 is shown in Additional file 5. In v3 cases, regions from tier 1 genes with less than 100\% coverage with a minimum of 20 reads (DP20) and specific positions within those regions affected by such limitation were included in each individual patient's report.

\section{Analytical sensitivity and specificity}

Prior to its use in the diagnostic setting, the clinical version of the panel (v3) was evaluated for sensitivity and specificity on a genotyped mixture of 10 lymphoblastoid cell lines. 1617/1624 variants with allele frequency $\geq 0.1$ were detected (1497/1503 SNVs and 120/121 indels), yielding a sensitivity of 0.9957 (>99.5\%). Additionally, $1,034,047 / 1034817$ true negative positions of the target region were called by the platform as not bearing SNVs or indels, representing a specificity of 0.9992 (> 99.9\%).

\section{Orthogonal validation of sequencing results}

All variants considered responsible for the SNHL phenotypes of the probands (Table 2) were successfully validated by approaches alternative to NGS. These included 25 instances of SNVs or indels (validated by PCR and Sanger sequencing) and 4 CNVs: 1 heterozygous partial duplication of CDH23 (exons 11-15), 1 homozygous deletion of $R D X$ exon 2 (both validated by breakpoint-specific PCR) and 2 homozygous STRC whole gene deletions (validated by qPCR and MLPA). Apart from these, 4 samples had heterozygous STRC CNVs (3 deletions and 1 duplication) all of which were validated by qPCR and MLPA (Additional file 8). These results indicate that our CNV calling procedure is highly specific.

\section{Performance at interfering highly homologous regions}

Genomic regions with high sequence homology cause misalignment of sequencing data and represent a major challenge for short-read NGS technologies. Out of the 199 genes included in the v3 panel, STRC, OTOA, ESPN and $K C N E 1$ contain a total of 22 interfering highly homologous regions (as defined in the Methods section), most of which overlap with those previously identified by Mandelker et al. [32] (Additional file 6). To avoid missing clinically relevant variants present in those target regions, the panel NGS reads from all samples were realigned to reference sequences containing only the STRC, OTOA, ESPN and KCNE1 loci, as previously described by us for the PMS2 gene in a cancer panel [12]. This approach revealed that all samples might potentially carry a pathogenic variant in the STRC gene: c.4057C > T, p.Gln1353* (coincident with the reference sequence for exon 20 from the $p S T R C$ pseudogene). To unequivocally discriminate the origin of this variant, LR-PCR specific for the STRC gene followed by Sanger sequencing was performed as described [28]. This approach discarded the potential genic origin of the variant in 28/50 samples; not enough DNA was available from 1 sample and no LR-PCR product was obtained from 21 . Of note, the average genomic DNA Integrity Number (DIN) of the 28 samples with successful LR-PCR was significantly higher than that of the remaining 21 samples (8.71 vs $7.21 ; p$-value $=1.8 \times 10^{-4}$; Student's T test), suggesting that DNA degradation precluded LR-PCR. Alternative approaches would be 
needed to discard or confirm the genic origin of the variant in those 21 samples.

\section{Analysis of causative variants and diagnostic yield} Of 50 cases with severe-to-profound SNHL not caused by GJB2/GJB6, OTOF or MT-RNR1 mutations, a genetic justification for their HL phenotype was found in 21 (42\%) after identifying 31 pathogenic/likely pathogenic variants in 16 genes: ACTG1, BSND, CDH23, CHD7, COL4A5, GATA3, MITF, MYO15A, P2RX2, POU3F4, PRPS1, RDX, SLC26A4, SOX10, STRC and USH2A (Tables 2 and 3). Three more cases had recessive variants of uncertain significance in homozygosis (affecting the LOXHD1 and SLC26A4 genes) or in hemizygosis (affecting the OTOA gene: $1 \mathrm{SNV}$ + heterozygous whole-gene $O T O A$ deletion), which were suspicious of pathogenicity, but did not fulfill ACMG criteria and, thus, were not counted nor reported as positives (Table 4). Had they been counted, the diagnostic yield would have been $48 \%(24 / 50)$.

In our cohort, $47.6 \%(10 / 21)$ of the unambiguously molecularly diagnosed patients had autosomal recessive (AR) inheritance patterns, 38.1\% (8/21) autosomal dominant $(\mathrm{AD})$, and $14.3 \%(3 / 21)$ were X-linked (Table 2$)$. The molecular basis of deafness was found in $44.4 \%$ (20/ 45) of the cases with symmetric SNHL, whereas only 1 of 5 cases with asymmetric SNHL was genetically diagnosed (Waardenburg syndrome caused by a MITF mutation) (Tables 2 and 3).

The most common SNHL causative genes in our prescreened population were ACTG1 (3 patients), USH2A (3 patients) and STRC (2 patients). Interestingly, 2 of 3 pathogenic variants in ACTG1 were de novo, as well as 1 GATA3 and 1 COL4A5 pathogenic variants.

$\mathrm{CNV}$ analysis identified causative variants in 4 of the 21 molecularly diagnosed patients (19\%): 2 with a homozygous complete STRC deletion, 1 with a previously unreported partial $C D H 23$ duplication (exons 11-15) in compound heterozygosity with a second pathogenic variant (missense), and 1 with a homozygous $R D X$ exon 2 deletion. One of the patients with a homozygous causative STRC deletion was also a carrier of a heterozygous substitution in TECTA, previously reported in the literature as a dominant pathogenic variant (c.3107G > A; p.Cys1036Tyr) [33]. However, revaluation of this variant according to ACMG guidelines reclassified it as a variant of uncertain significance (it only fulfilled ACMG pathogenicity criteria PP1 and PP3).

In total, 451 variants, of which 406 were unique, in 121 distinct genes were identified in the full cohort of $50 \mathrm{pa}$ tients: 394 variants in 97 genes were identified in tier 1 . Tier 2 added 57 variants that contributed to the overall interpretation burden. No tier 2 variant was considered responsible for the SNHL phenotype (Fig. 1).

199/394 (50.5\%) and 45/57 (78.9\%) of the identified tier 1 and tier 2 variants, respectively, were absent from the databases (HGMD professional and ClinVar). Fifteen of them (all from tier 1), were classified as pathogenic or likely pathogenic and responsible for the SNHL phenotype of the patient (Fig. 1). Globally, those 15 variants were considered responsible for the SNHL phenotype in 13 cases. As a result, $61.9 \%$ of the genetically diagnosed cases (13/21) were explained by variants not described in the databases (Fig. 2 and Table 2). Moreover, of 25 non-redundant variants classified as pathogenic (DM) by HGMD for hearingrelated phenotypes, after looking for plausible published support in the literature, solid evidence could only be found for 13 of them (52\%) (Additional file 9). Of the 12 variants considered DM by HGMD but, in our view, without enough supporting evidence, 3 (25\%) were also considered as Pathogenic/Likely pathogenic by at least one ClinVar submitter (Additional file 9). To deal with these limitations, an average of $40 \mathrm{~min}$ of expert review was dedicated per variant. With an average of 9 variants per case, this represents $360 \mathrm{~min}(6 \mathrm{~h})$ per case. These results highlight the importance of manual interpretation and curation for clinical classification of variants, even for those considered as (potentially) disease causing by reputable databases.

\section{Increase of clinical sensitivity by analysis of syndromic genes on apparently non-syndromic SNHL}

$28.6 \%$ of the genetically diagnosed cases $(6 / 21)$ had a previously unrecognized syndrome: Barakat (1 patient), Usher type 2A (3 patients) and Waardenburg (2 patients) (Table 2 ). These unexpected syndromic findings not only increased the diagnostic yield, but they provided diagnostics of utmost clinical relevance. Additionally, 6 patients carried pathogenic variants in genes associated with syndromic and non-syndromic conditions (Table 2): 1 had variants associated with Pendred syndrome and DFNB4, 1 with Bartter syndrome type IV and DFNB73, 1 with Usher syndrome 1D and DFNB12 and 3 with Baraitser-Winter type 2 and DFNA20/DFNA26. These patients will need close follow-up in case syndromic features develop.

\section{Discussion}

Hearing loss is one of the most genetically heterogeneous disorders known. $60 \%$ of cases are believed to be of genetic origin and $30 \%$ of them syndromic [34]. Due to its high diagnostic yield $[35,36]$, the newest ACMG guidelines include NGS testing in the standard SNHL diagnostic algorithm [1], whereas the use of non-genetic tests should be considered case-by-case, usually as a complement to genetic testing. However, except for the preeminent relevance of GJB2 mutations, little is known about the frequency of SNHL variants in Europeans [9, 37].

Our results contribute to define the mutation spectra in the Spanish population, underlining the SNHL genetic heterogeneity, as the causative variants of 21 patients affected 16 different genes. The genes most commonly altered in 


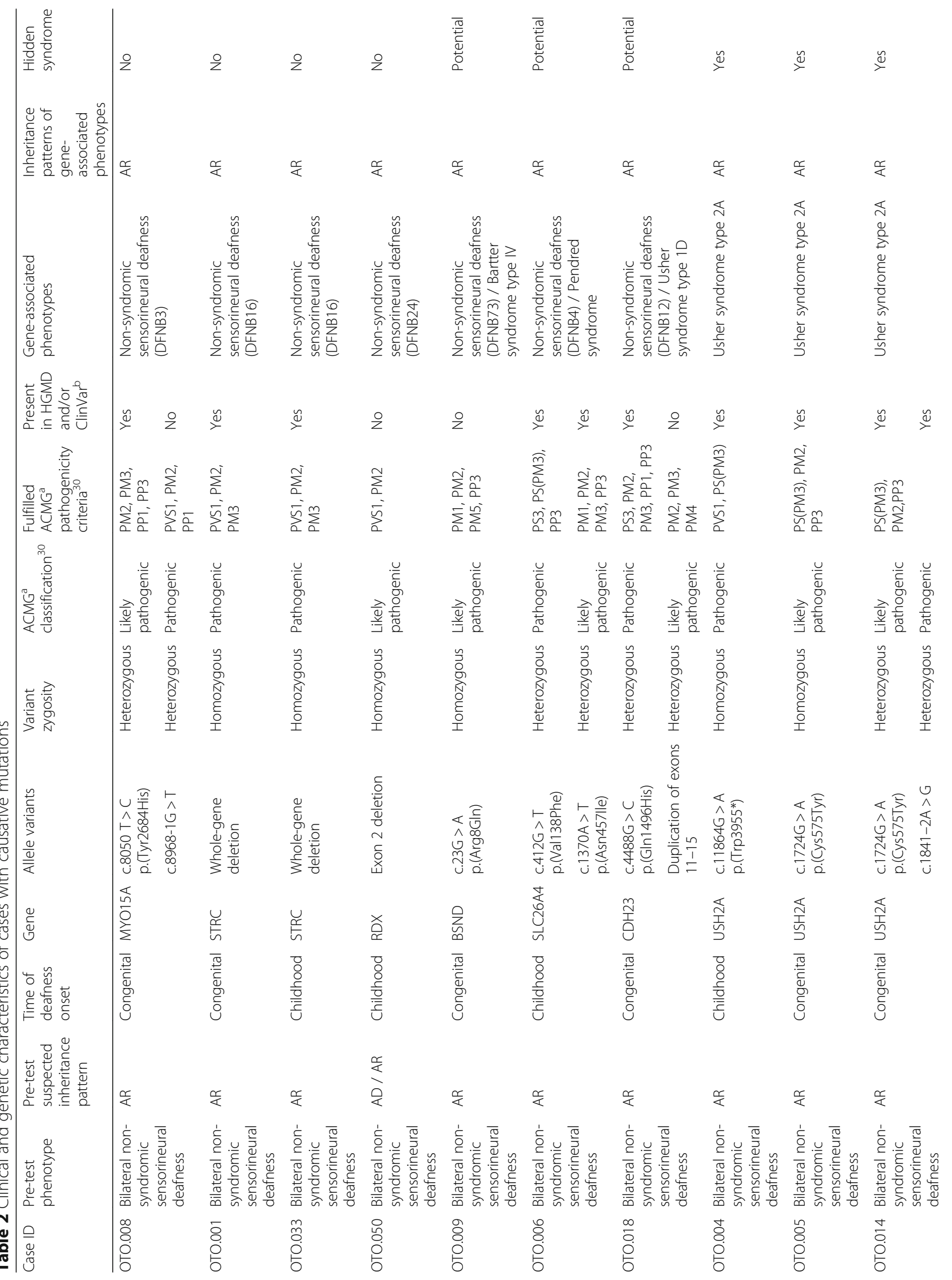




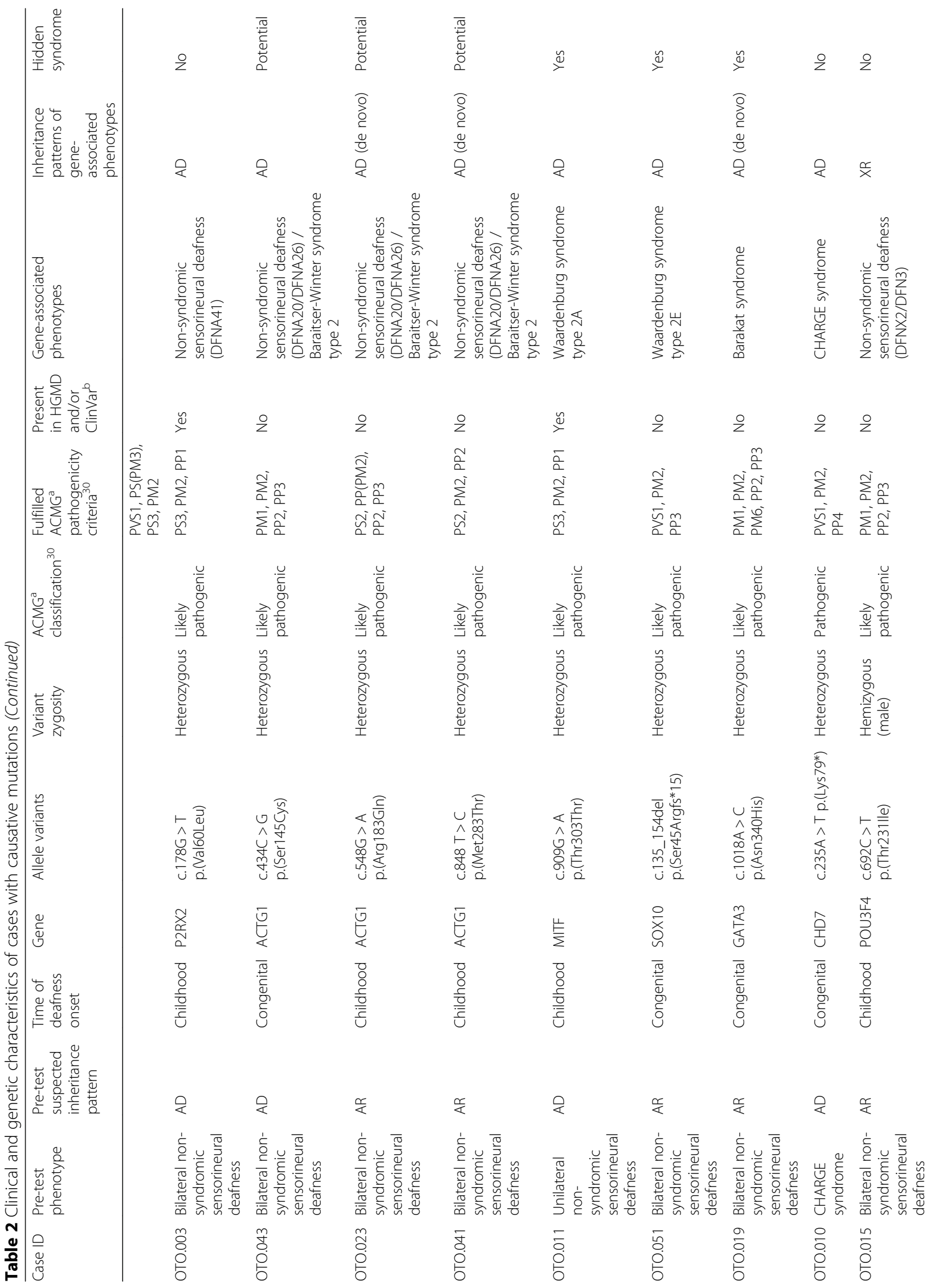




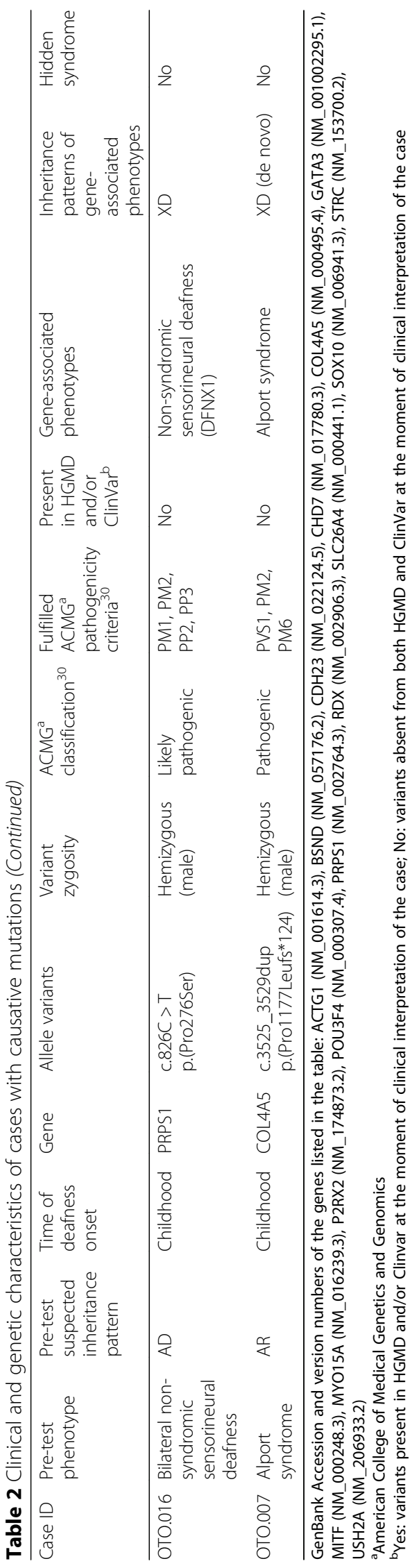


our pre-screened population were ACTG1 $(n=3), U S H 2 A$ $(\mathrm{n}=3)$ and STRC $(\mathrm{n}=3)$. Although variants in $U S H 2 A$ and STRC are often reported as common causes of SNHL [28, 37-40], the identification of ACTG1 as the most frequent causative gene in our cohort is surprising.

ACTG1 variants are responsible for DFNA20/DFNA26 and type 2 Baraitser-Winter syndrome. None of our 3 cases has syndromic features to date, and all of them had earlyonset profound SNHL, expanding the phenotypic spectrum of ACTG1, usually associated to post-lingual and progressive SNHL [41, 42], to prelocutive SNHL. Since none of the 3 causative variants had been described and 2 of them were de novo, a targeted hot-spot mutation assay or an AR oriented gene panel (the 2 de novo mutations took place in patients without familial background, simulating a recessive pattern) would have missed them. Therefore, the prevalence of ACTG1 pathogenic variants could be higher, and its expression pattern more variable, than previously thought [43].

Our $38.1 \%$ rate of syndromic SNHL (8/21, including 2 syndromes diagnosed before and 6 after NGS genetic testing) is within expected rates. In contrast, our $38 \%$ incidence of AD and 14\% of X-linked SNHL are higher than expected [44]. This might reflect the consequences of pre-screening, which excluded the most common AR (GJB2/GJB6 and OTOF) and mitochondrial (MT-RNR1) mutations [2, 31, 45]. However, since in our patients $50 \%(4 / 8)$ of causative dominant variants were de novo (2 in ACTG1, 1 in GATA3; and 1 in COL4A5, Table 2) it might also be the consequence of using an unbiased NGS panel, able to identify unexpected de novo variants. Despite the limited size of our cohort, our de novo detection rate is strikingly similar to that reported recently in whole-exome sequencing (WES) studies for different clinical indications (37-68\%) $[35,46]$.

A technical difficulty encountered for the implementation of a clinical-grade test was the presence of highly homologous pseudogene background for some of the target genes included in the panel (Additional file 6), especially STRC and OTOA. The measures proposed to deal with this problem (gene-restrictive realignment of sequencing results and validation of putative causative variants by gene-specific methods) should reduce misdiagnosis. Moreover, the STRC gene, one of the largest contributors to AR SNHL [28, 47, 48], is also a common site for large deletions [28], and CNVs can be refractory to general NGS approaches. As displayed in our population, where $19 \%$ of cases $(4 / 21)$ were justified by CNVs, large genetic rearrangements are increasingly recognized as a common cause of genetic hearing loss, accounting for $13-19 \%$ of all causative variants [5, 48-50]. Therefore, CNV analysis should be a requirement for all patients undergoing genetic testing for SNHL. In this regard, our $100 \%$ validation rate of NGS-detected STRC CNVs by qPCR and MLPA is encouraging (Additional file 8).
Diagnostic rates of up to $60 \%$ are expected in patients with suspected AR congenital deafness. This percentage strongly declines for $\mathrm{AD}$ hearing loss, especially with the increase in the age of onset $[5,48]$. In our series, as in most of published studies [5, 48, 51], prior to comprehensive genetic testing, patients were prescreened for common deafness mutations (in our cohort, GJB2/GJB6, OTOF and $M T-R N R 1$, selected for their high prevalence in Spain [7, 31]). Mutations in the GJB2 gene are among the most frequent causes for congenital hearing loss. The prevalence of its biallelic pathogenic mutations among non-syndromic SNHL cases ranges geographically from $0 \%$ to over $50 \%[3$, 52-54]. Recent analyses show a worldwide and European prevalence of around 13\%, increasing in $<5$ year-old patients $[2,3]$. In our laboratory, GJB2/GJB6, OTOF and MT-RNR1 prescreening of 180 patients identified the cause of deafness in 34 (18.9\%) (unpublished results). This figure, combined with the $42-48 \%$ diagnostic rate of our panel in pre-screened patients ( $48 \%$ considering as causative the highly suspicious variants of Table 4), allows us to estimate that combining prescreening with our panel will lead to a diagnosis in about $53-58 \%$ of patients.

Our $42-48 \%$ detection rate is slightly higher than the average reported with NGS-panels: $41 \%(10-83 \%)$ for a mix of pre-screened and not pre-screened patients $[5,9$, $28,48,51]$. Proper target region coverage and bioinformatics approaches shouldn't be underestimated for maximizing clinical sensitivity. Additionally, the inclusion of syndromic genes, revealing 'hidden syndromes', increased the diagnostic yield. The 6 a priori clinically unrecognized syndromes in our cohort diagnosed after genetic testing (Table 2), representing $28.6 \%$ of the genetically diagnosed cases, are a proof of concept of how NGS is changing medicine. In fact, undiagnosed syndromes in families with apparently non-syndromic SNHL are increasingly reported [55-58], expanding the phenotypes associated with SNHL-syndromes [35]. Moreover, 6 patients in our series had pathogenic variations in genes associated with both syndromic and non-syndromic HL: $\mathrm{CDH} 23$ (Usher syndrome 1D and DFNB12), ACTG1 (Baraitser-Winter syndrome type 2 and DFNA20/DFNA26), BSND (Bartter syndrome type IV and DNFB73) or SLC26A4 (Pendred syndrome and DFNB4) (Table 2). Close follow-up of these patients is mandatory, since syndromic features may develop.

The clinical interpretation of genomic findings is a cornerstone of NGS diagnostic pipelines. Beyond deafness, a recent study indicated that as many as $30 \%$ of all disease-causing genetic variants cited in the literature may have been misinterpreted [59]. In our cohort, manual interpretation of variants required an average of $6 \mathrm{~h} /$ case, dedicated to in-depth review of the databases and scientific literature, under the perspective of the patient's phenotype and family history, which is imperative for accurate variant interpretation $[11,60]$. 
Table 3 Clinical characteristics of cases without causative mutations

\begin{tabular}{|c|c|c|c|}
\hline Case ID & Phenotype & $\begin{array}{l}\text { Suspected inheritance } \\
\text { pattern }\end{array}$ & $\begin{array}{l}\text { Time of deafness } \\
\text { onset }\end{array}$ \\
\hline OTO.017 & Bilateral non-syndromic sensorineural deafness & $A R$ & Congenital \\
\hline OTO.021 & $\begin{array}{l}\text { Bilateral sensorineural deafness. Nystagmus, strabismus, delay in psychomotor development } \\
\text { and autism spectrum disorder }\end{array}$ & $A R$ & Congenital \\
\hline OTO.024 & Bilateral non-syndromic sensorineural deafness & $A R$ & Childhood \\
\hline OTO.025 & Bilateral non-syndromic sensorineural deafness & $A R$ & Childhood \\
\hline OTO.026 & Unilateral non-syndromic sensorineural deafness & $A R$ & Childhood \\
\hline OTO.027 & Bilateral non-syndromic sensorineural deafness & $A R$ & Congenital \\
\hline OTO.028 & Bilateral non-syndromic sensorineural deafness & $A R$ & Childhood \\
\hline OTO.029 & Unilateral non-syndromic sensorineural deafness & $A R$ & Congenital \\
\hline OTO.030 & $\begin{array}{l}\text { Unilateral sensorineural deafness. Connective tissue problems, digestive problems, urinary } \\
\text { reflux and knee hypermobility }\end{array}$ & $A R$ & Childhood \\
\hline OTO.032 & Unilateral non-syndromic sensorineural deafness & $A R$ & Congenital \\
\hline OTO.034 & Bilateral non-syndromic sensorineural deafness & $A R$ & Childhood \\
\hline OTO.035 & Bilateral non-syndromic sensorineural deafness & $A R$ & Childhood \\
\hline OTO.038 & Bilateral non-syndromic sensorineural deafness & $A R$ & Unknown \\
\hline ОТО.040 & Bilateral non-syndromic sensorineural deafness & $A R$ & Childhood \\
\hline OTO.042 & Bilateral non-syndromic sensorineural deafness & $A R$ & Congenital \\
\hline OTO.044 & Bilateral non-syndromic sensorineural deafness & $A R$ & Congenital \\
\hline OTO.045 & Bilateral non-syndromic sensorineural deafness & AR & Congenital \\
\hline OTO.046 & Bilateral non-syndromic sensorineural deafness & $A R$ & Childhood \\
\hline OTO.049 & Bilateral non-syndromic sensorineural deafness & $A R$ & Adulthood \\
\hline OTO.052 & $\begin{array}{l}\text { Bilateral sensorineural deafness. Lobe of the auricular pavilion with grooves. Polysyndactyly in } \\
\text { hands and feet. Hypospadias }\end{array}$ & $A R$ & Congenital \\
\hline OTO.053 & Bilateral non-syndromic sensorineural deafness & $A R$ & Childhood \\
\hline OTO.036 & Bilateral non-syndromic sensorineural deafness & $A R / A D$ & Childhood \\
\hline OTO.039 & Bilateral non-syndromic sensorineural deafness & $A R / A D$ & Adulthood \\
\hline OTO.020 & Bilateral non-syndromic sensorineural deafness & $A D$ & Childhood \\
\hline OTO.022 & Bilateral non-syndromic sensorineural deafness & $A D$ & Congenital \\
\hline OTO.031 & Bilateral non-syndromic sensorineural deafness & $A D$ & Childhood \\
\hline OTO.037 & Bilateral non-syndromic sensorineural deafness & $A D$ & Adulthood \\
\hline OTO.047 & Bilateral non-syndromic sensorineural deafness & $A D$ & Childhood \\
\hline ОTO.048 & Bilateral non-syndromic sensorineural deafness & $\mathrm{AD}$ & Childhood \\
\hline
\end{tabular}

To date, several studies using NGS for genetic diagnosis of deafness have been published, involving either gene panels or WES $[5,61]$. When WES is ordered, sequenced regions not only include genes of interest ("targeted disease-specific panels" such as the one presented in this paper), but also all exons of all genes in the genome. Although WES avoids the need for specific gene panel enrichment, a literature-based selection of the genes involved in the pathology is anyway required for results intepretation. WES increases the requirements for sequencing resources, complicates the analysis and normally provides insufficient coverage of key target regions [29]. Moreover, WES carries increased chance of secondary findings (variants identified in genes unrelated to the primary medical reason for testing [62]), which introduce noise into the genetic counseling procedure. A comparison of a disease-focused panel versus WES for inherited eye diseases found improved accuracy and performance of the disease-specific panel, a finding that can be translated to hearing loss panels [63]. For these reasons, disease-focused genetic tests have become the standard when evaluating hearing loss [64]. However, WES does have an advantage: the ability to identify alterations in genes not definitely associated with the disease yet. To minimize this disadvantage, a tiered approach was implemented: tier 


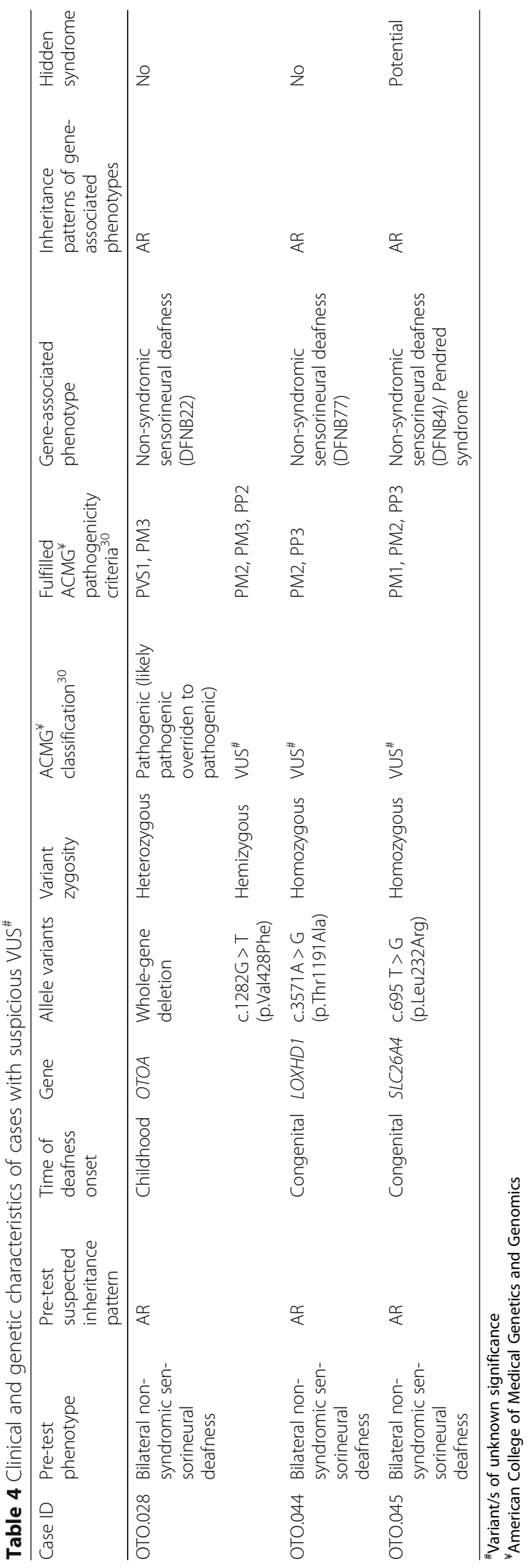




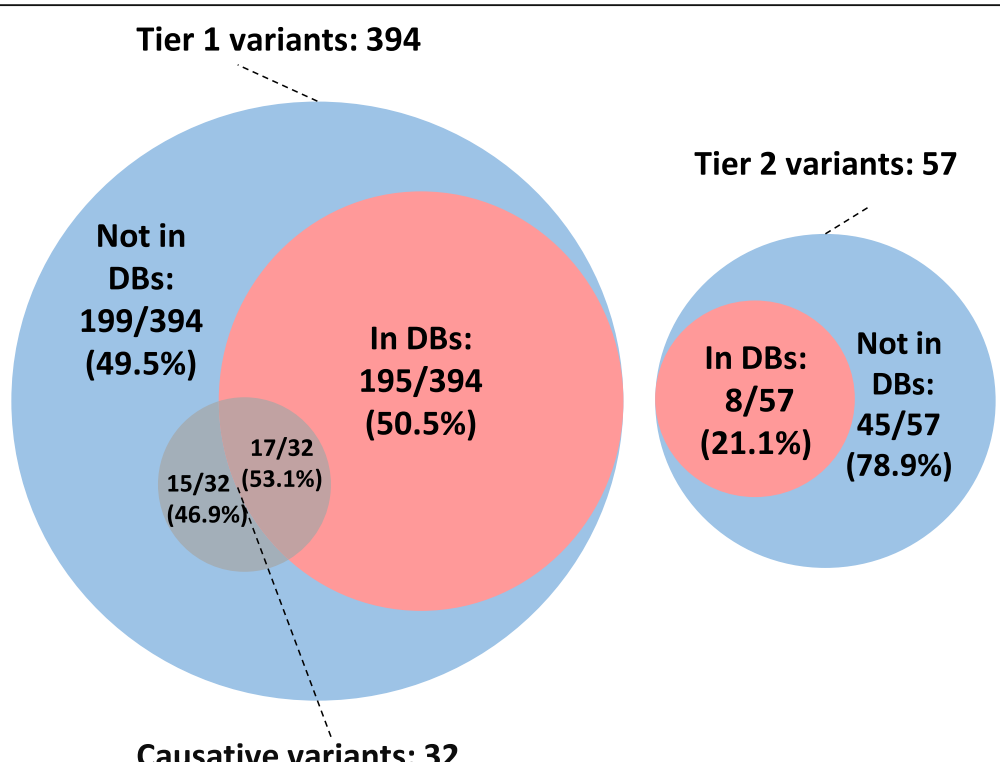

Fig. 1 Presence/absence of total and causative variants in databases. Circles represent total numbers of tier 1 (left) and tier 2 (right) variants (not to scale), their presence in the HGMD professional and/or ClinVar databases (in DBs) or their absence from both databases (not in DBs) at the moment of case evaluation, and the distribution of the 32 variants considered causative of $\mathrm{HL}$ within these categories

1 includes all genes consistently associated with SNHL, whereas tier 2 includes genes without sufficient clinical validity to be included in clinical testing. Non-systematic reporting of tier 2 genes reduces the uncertainty and simplifies the genetic counseling procedure. However,

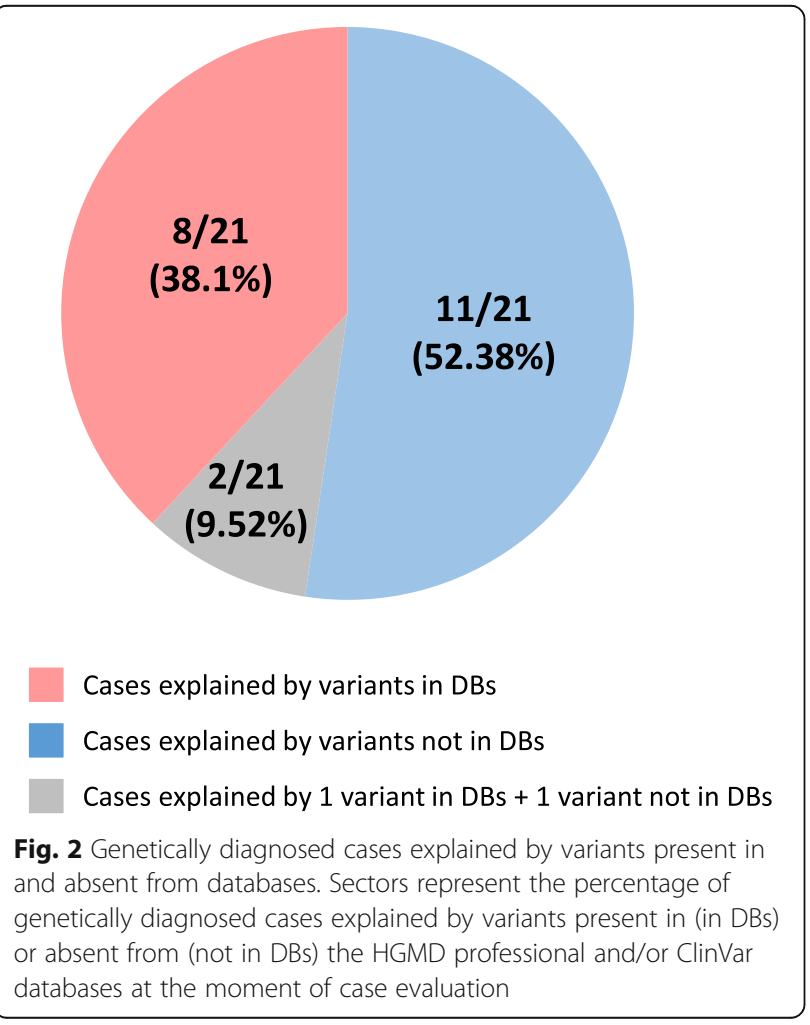

meanwhile, it facilitates fast pipeline incorporation of clinically validated genes, as soon as confirmatory discoveries are published.

\section{Conclusions}

Our results underscore the importance of a comprehensive approach with careful gene selection to the genetic diagnosis of SNHL. Here, we contribute to show that, with the right methodology, NGS can be transferred to the clinical practice, boosting the yield of SNHL genetic diagnosis to $50-60 \%$ (including GJB2/GJB6 alterations), improving diagnostic/prognostic accuracy, refining genetic and reproductive counseling and revealing clinically relevant undiagnosed syndromes. Lowering cost and increasing quality of WES and whole-genome sequencing (WGS) will probably prompt substitution of physical gene panels by non-targeted approaches. However, WES/WGS results are likely to be filtered through in-silico gene panels, based on a meticulously curated gene selection, such as the gene-set of the current panel. Thus, the methodology implemented on the present study is expected to be useful in the years to come. Since comprehensive genetic testing using NGS should be the standard of care for genetic evaluation of patients with SNHL, hereditary deafness should become a paradigm on the raising field of precision medicine. In this context, we expect that the use of the current platform, or others developed on the knowledge presented herein, will help to bring to the clinical arena the advantages of predictive and preventive SNHL genetic testing. 


\section{Additional files}

Additional file 1: List of phenotypes potentially related to hearing defects used as keywords for initial query on HGMD. (XLSX 16 kb)

Additional file 2: Tier 1 and tier 2 genes included in $\vee 1$ of the panel. (XLSX $13 \mathrm{~kb}$ )

Additional file 3: Tier 1 and tier 2 genes included in v2 of the panel. (XLSX $13 \mathrm{~kb}$ )

Additional file 4: Cases analyzed with each panel version. (XLSX $10 \mathrm{~kb}$ )

Additional file 5: Coverages and callabilities for every tier 1 and tier 2 gene on v3 samples. (XLSX $31 \mathrm{~kb}$ )

Additional file 6: Highly homologous conflictive regions. (XLSX $11 \mathrm{~kb}$ )

Additional file 7: Primers used to validate causative (pathogenic and likely pathogenic) variants. (XLSX $13 \mathrm{~kb}$ )

Additional file 8: Samples with STRC CNVs. (XLSX 9 kb)

Additional file 9: Variants identified in our cohort classified as pathogenic (DM) by HGMD for hearing-related phenotypes. (XLSX $11 \mathrm{~kb}$ )

\section{Abbreviations}

ACMG: Americal college of medical genetics and genomics; AD: Autosomal dominant; AR: Autosomal recessive; CNVs: Copy number variations; DIN: DNA integrity number; HL: Hearing loss; NGS: Next-generation sequencing; SNHL: Sensorineural hearing loss; SNVs: Single nucleotide variants; WES: Whole-exome sequencing; WGS: Whole-genome sequencing

\section{Acknowledgements}

We are grateful to all participating patients and their families.

\section{Funding}

Work performed at IMOMA for this project was partially supported by a grant from Fundación María Cristina Masaveu Peterson. Work performed at DREAMgenics was partially supported by University of Oviedo Foundation grants (D.C., P.C.P.).

\section{Availability of data and materials}

The datasets used and/or analysed during the current study are available from the corresponding author on reasonable request.

\section{Authors' contributions}

RuC participated in study design, interpretation of results and writing of the manuscript; MD performed most of the experimental work and contributed to interpretation of results; GAC contributed to experimental work and results interpretation; DC, PC and GRO, performed bioinformatic analyses; RA and NSD contributed to experimental work; $\mathrm{RaC}$ contributed to results interpretation; AP, MVD, NGG, IH, JLL. ARA, CTB, JR, NG, JRGM, FNB, JAG, AMG, MC, MIG and BGB provided patient samples and associated clinical data; JC participated in study design, interpretation of results and writing of the manuscript; all authors commented on the manuscript and approved the submitted version.

\section{Ethics approval and consent to participate}

The study was approved by the Comité de Ética de Investigación del Principado de Asturias (research project \#75/14). Consent was obtained from all patients or their parents.

\section{Consent for publication}

Not applicable.

\section{Competing interests}

The following authors are currently employed by IMOMA or DREAMgenics, the companies involved in the development and exploitation of the OTOgenics ${ }^{\text {TM }}$ platform: IMOMA: Ru.C. (Physician in Chief), M.D. (Clinical Molecular Geneticist), G.A.C. (Biotechnologist), N.S.D. (Lab. Technician), R.A. (Lab. Technician), Ra.C. (Molecular Biologist) and J.C. (Scientific Director); DREAMgenics: D.C. (Bioinformatitian), P.C.P. (Bioinformatitian) and G.R.O. (Bioinformatitian, C.S.O. and C.E.O.). G.R.O. is a shareholder of DREAMgenics. The other authors declare no conflict of interest.

\section{Publisher's Note}

Springer Nature remains neutral with regard to jurisdictional claims in published maps and institutional affiliations.

\section{Author details}

${ }^{1}$ Instituto de Medicina Oncológica y Molecular de Asturias (IMOMA) S. A Avda. Richard Grandío s/n, 33193 Oviedo, Spain. ²Disease Research And Medicine (DREAMgenics) S. L., Oviedo, Spain. ${ }^{3}$ Hospital Universitario Central de Asturias, Oviedo, Spain. ${ }^{4}$ Hospital Álvaro Cunqueiro, Vigo, Spain. ${ }^{5}$ Hospital Universitario Son Espases, Palma de Mallorca, Spain. ${ }^{6}$ Hospital Universitario Río Hortega, Valladolid, Spain. ${ }^{7}$ Hospital Universitario Marqués de Valdecilla, Santander, Spain. ${ }^{8}$ Instituto de Investigación Biomédica de Salamanca, Salamanca, Spain.

Received: 20 March 2018 Accepted: 14 June 2018 Published online: 09 July 2018

\section{References}

1. Alford RL, Arnos KS, Fox M, Lin JW, Palmer CG, Pandya A, Rehm HL, Robin $\mathrm{NH}$, Scott DA, Yoshinaga-Itano C, et al. American College of Medical Genetics and Genomics guideline for the clinical evaluation and etiologic diagnosis of hearing loss. Genet Med. 2014;16(4):347-55.

2. Burke WF, Warnecke $A$, Schoner-Heinisch A, Lesinski-Schiedat A, Maier $H$, Lenarz T. Prevalence and audiological profiles of GJB2 mutations in a large collective of hearing impaired patients. Hear Res. 2016;333:77-86.

3. Chan DK, Chang KW. GJB2-associated hearing loss: systematic review of worldwide prevalence, genotype, and auditory phenotype. Laryngoscope. 2014;124(2):E34-53.

4. Sabatini LM, Mathews C, Ptak D, Doshi S, Tynan K, Hegde MR, Burke TL, Bossler AD. Genomic sequencing procedure microcosting analysis and health economic cost-impact analysis: A Report of the Association for Molecular Pathology. J Mol Diagn. 2016;18(3):319-28

5. Shearer $A E$, Smith RJ. Massively parallel sequencing for genetic diagnosis of hearing loss: the new standard of care. Otolaryngol Head Neck Surg. 2015; 153(2):175-82.

6. Nunez-Batalla F, Jaudenes-Casaubon C, Sequi-Canet JM, Vivanco-Allende A, Zubicaray-Ugarteche J, Cabanillas-Farpon R. Aetiological diagnosis of child deafness: CODEPEH recommendations. Acta Otorrinolaringol Esp. 2017:68(1):43-55.

7. Cabanillas Farpón R, Cadiñanos Bañales J. Hereditary hearing loss: genetic counselling. Acta Otorrinolaringol Esp. 2012;63(3):218-29.

8. Rahman S, Ecob R, Costello H, Sweeney MG, Duncan AJ, Pearce K, Strachan D, Forge A, Davis A, Bitner-Glindzicz M. Hearing in 44-45 year olds with $\mathrm{m}$. $1555 \mathrm{~A}>\mathrm{G}$, a genetic mutation predisposing to aminoglycoside-induced deafness: a population based cohort study. BMJ Open. 2012;2:e000411.

9. Sommen M, Schrauwen I, Vandeweyer G, Boeckx N, Corneveaux JJ, van den Ende J, Boudewyns A, De Leenheer E, Janssens S, Claes K, et al. DNA diagnostics of hereditary hearing loss: a targeted resequencing approach combined with a mutation classification system. Hum Mutat. 2016:37(8):812-9.

10. Geleoc GS, Holt JR. Sound strategies for hearing restoration. Science. 2014; 344(6184):1241062.

11. Abou Tayoun AN, Al Turki SH, Oza AM, Bowser MJ, Hernandez AL, Funke BH, Rehm HL, Amr SS. Improving hearing loss gene testing: a systematic review of gene evidence toward more efficient next-generation sequencing-based diagnostic testing and interpretation. Genet Med. 2016;18(6):545-53.

12. Cabanillas R, Diñeiro M, Castillo D, Pruneda PC, Penas C, Cifuentes GA, de Vicente A, Durán NS, Álvarez R, Ordóñez GR, et al. A novel molecular diagnostics platform for somatic and germline precision oncology. Mol Genet Genomic Med. 2017;5(4):336-59.

13. Jennings $L$, Arcila ME, Corless C, Kamel-Reid S, Lubin IM, Pfeifer J, TempleSmolkin RL, Voelkerding KV, Nikiforova MN. Guidelines for validation of nextgeneration sequencing-based oncology panels: A Joint Consensus Recommendation of the Association for Molecular Pathology and College of American Pathologists. J Mol Diagn. 2017;19(3):341-65.

14. Li H, Durbin R. Fast and accurate long-read alignment with burrowswheeler transform. Bioinformatics. 2010:26(5):589-95.

15. Li H, Handsaker B, Wysoker A, Fennell T, Ruan J, Homer N, Marth G, Abecasis $\mathrm{G}$, Durbin $\mathrm{R}$, Genome project data processing $\mathrm{S}$. The sequence alignment map format and SAMtools. Bioinformatics. 2009;25(16):2078-9. 
16. Puente XS, Pinyol M, Quesada V, Conde L, Ordonez GR, Villamor N, Escaramis G, Jares P, Bea S, Gonzalez-Diaz M, et al. Whole-genome sequencing identifies recurrent mutations in chronic lymphocytic leukaemia. Nature. 2011:475(7354):101-5.

17. Valdes-Mas R, Bea S, Puente DA, Lopez-Otin C, Puente XS. Estimation of copy number alterations from exome sequencing data. PLoS One. 2012;7(12):e51422

18. Kumar P, Henikoff S, Ng PC. Predicting the effects of coding nonsynonymous variants on protein function using the SIFT algorithm. Nat Protoc. 2009;4(7):1073-81.

19. Adzhubei IA, Schmidt S, Peshkin L, Ramensky VE, Gerasimova A, Bork P, Kondrashov AS, Sunyaev SR. A method and server for predicting damaging missense mutations. Nat Methods. 2010;7(4):248-9.

20. Choi Y, Sims GE, Murphy S, Miller JR, Chan AP. Predicting the functional effect of amino acid substitutions and indels. PLoS One. 2012;7(10):e46688.

21. Reva B, Antipin Y, Sander C. Predicting the functional impact of protein mutations: application to cancer genomics. Nucleic Acids Res. 2011;39(17):e118.

22. Schwarz JM, Cooper DN, Schuelke M, Seelow D. MutationTaster2: mutation prediction for the deep-sequencing age. Nat Methods. 2014;11(4):361-2.

23. Chun S, Fay JC. Identification of deleterious mutations within three human genomes. Genome Res. 2009;19(9):1553-61.

24. Dong C, Wei P, Jian X, Gibbs R, Boerwinkle E, Wang K, Liu X. Comparison and integration of deleteriousness prediction methods for nonsynonymous SNVs in whole exome sequencing studies. Hum Mol Genet. 2015;24(8):2125-37.

25. Shihab HA, Gough J, Mort M, Cooper DN, Day IN, Gaunt TR. Ranking nonsynonymous single nucleotide polymorphisms based on disease concepts. Hum Genomics. 2014;8:11.

26. Jagadeesh KA, Wenger AM, Berger MJ, Guturu H, Stenson PD, Cooper DN, Bernstein JA, Bejerano G. M-CAP eliminates a majority of variants of uncertain significance in clinical exomes at high sensitivity. Nat Genet. 2016; 48(12):1581-6.

27. Davydov EV, Goode DL, Sirota M, Cooper GM, Sidow A, Batzoglou S. Identifying a high fraction of the human genome to be under selective constraint using GERP++. PLoS Comput Biol. 2010;6(12):e1001025.

28. Mandelker D, Amr SS, Pugh T, Gowrisankar S, Shakhbatyan R, Duffy E, Bowser M, Harrison B, Lafferty K, Mahanta L, et al. Comprehensive diagnostic testing for stereocilin: an approach for analyzing medically important genes with high homology. J Mol Diagn. 2014;16(6):639-47.

29. Shearer AE, Black-Ziegelbein EA, Hildebrand MS, Eppsteiner RW, Ravi H, Joshi S, Guiffre AC, Sloan CM, Happe S, Howard SD, et al. Advancing genetic testing for deafness with genomic technology. J Med Genet. 2013;50(9):62734.

30. Richards S, Aziz N, Bale S, Bick D, Das S, Gastier-Foster J, Grody WW, Hegde M, Lyon E, Spector E, et al. Standards and guidelines for the interpretation of sequence variants: a joint consensus recommendation of the American College of Medical Genetics and Genomics and the Association for Molecular Pathology. Genet Med. 2015;17(5):405-24.

31. Gallo-Teran J, Morales-Angulo C, Rodriguez-Ballesteros M, Moreno-Pelayo MA, del Castillo I, Moreno F. Prevalence of the 35delG mutation in the GJB2 gene, del (GJB6-D13S1830) in the GJB6 gene, Q829X in the OTOF gene and A1555G in the mitochondrial 12S rRNA gene in subjects with non-syndromic sensorineural hearing impairment of congenital/childhood onset. Acta Otorrinolaringol Esp. 2005;56(10):463-8.

32. Mandelker D, Schmidt RJ, Ankala A, McDonald Gibson K, Bowser M, Sharma H, Duffy E, Hegde M, Santani A, Lebo M, et al. Navigating highly homologous genes in a molecular diagnostic setting: a resource for clinical next-generation sequencing. Genet Med. 2016;18(12):1282-9.

33. Hildebrand MS, Morin M, Meyer NC, Mayo F, Modamio-Hoybjor S, Mencia A Olavarrieta L, Morales-Angulo C, Nishimura CJ, Workman H, et al. DFNA8/12 caused by TECTA mutations is the most identified subtype of nonsyndromic autosomal dominant hearing loss. Hum Mutat. 2011;32(7):825-34.

34. Toumpas CJ, Clark J, Harris A, Beswick R, Nourse CB. Congenital cytomegalovirus infection is a significant cause of moderate to profound sensorineural hearing loss in Queensland children. J Paediatr Child Health. 2015;51(5):541-4.

35. Retterer K, Juusola J, Cho MT, Vitazka P, Millan F, Gibellini F, Vertino-Bell A, Smaoui $\mathrm{N}$, Neidich J, Monaghan KG, et al. Clinical application of whole-exome sequencing across clinical indications. Genet Med. 2016;18(7):696-704.

36. Millan F, Cho MT, Retterer K, Monaghan KG, Bai R, Vitazka P, Everman DB, Smith $B$, Angle $B$, Roberts $V$, et al. Whole exome sequencing reveals de novo pathogenic variants in KAT6A as a cause of a neurodevelopmental disorder. Am J Med Genet A. 2016;170(7):1791-8.
37. Hilgert N, Smith RJ, Van Camp G. Forty-six genes causing nonsyndromic hearing impairment: which ones should be analyzed in DNA diagnostics? Mutat Res. 2009;681(2-3):189-96.

38. Reardon W, Coffey R, Phelps PD, Luxon LM, Stephens D, Kendall-Taylor P, Britton KE, Grossman A, Trembath R. Pendred syndrome-100 years of underascertainment? QJM. 1997;90(7):443-7.

39. Bonnet C, Riahi Z, Chantot-Bastaraud S, Smagghe L, Letexier M, Marcaillou C, Lefevre GM, Hardelin JP, El-Amraoui A, Singh-Estivalet A, et al. An innovative strategy for the molecular diagnosis of usher syndrome identifies causal biallelic mutations in 93\% of European patients. Eur J Hum Genet. 2016;24(12):1730-8.

40. Yoshimura H, Miyagawa M, Kumakawa K, Nishio SY, Usami S. Frequency of usher syndrome type 1 in deaf children by massively parallel DNA sequencing. J Hum Genet. 2016;61(5):419-22.

41. Kemerley A, Sloan C, Pfeifer W, Smith R, Drack A. A novel mutation in ACTG1 causing Baraitser-winter syndrome with extremely variable expressivity in three generations. Ophthalmic Genet. 2017;38(2):152-6.

42. Yuan Y, Gao X, Huang B, Lu J, Wang G, Lin X, Qu Y, Dai P. Phenotypic heterogeneity in a DFNA20/26 family segregating a novel ACTG1 mutation. BMC Genet. 2016;17:33.

43. Morin M, Bryan KE, Mayo-Merino F, Goodyear R, Mencia A, Modamio-Hoybjor S, del Castillo I, Cabalka JM, Richardson G, Moreno F, et al. In vivo and in vitro effects of two novel gamma-actin (ACTG1) mutations that cause DFNA20/26 hearing impairment. Hum Mol Genet. 2009;18(16):3075-89.

44. Sommen M, Wuyts W, Van Camp G. Molecular diagnostics for hereditary hearing loss in children. Expert Rev Mol Diagn. 2017;17(8):751-60.

45. Migliosi V, Modamio-Hoybjor S, Moreno-Pelayo MA, Rodriguez-Ballesteros M, Villamar M, Telleria D, Menendez I, Moreno F, Del Castillo I. Q829X, a novel mutation in the gene encoding otoferlin (OTOF), is frequently found in Spanish patients with prelingual non-syndromic hearing loss. J Med Genet. 2002;39(7):502-6.

46. Posey JE, Harel T, Liu P, Rosenfeld JA, James RA, Coban Akdemir ZH, Walkiewicz M, Bi W, Xiao R, Ding Y, et al. Resolution of disease phenotypes resulting from multilocus genomic variation. N Engl J Med. 2017;376(1):21-31.

47. Francey LJ, Conlin LK, Kadesch HE, Clark D, Berrodin D, Sun Y, Glessner J, Hakonarson H, Jalas C, Landau C, et al. Genome-wide SNP genotyping identifies the Stereocilin (STRC) gene as a major contributor to pediatric bilateral sensorineural hearing impairment. Am J Med Genet A. 2012;158A(2):298-308.

48. Zazo Seco C, Wesdorp M, Feenstra I, Pfundt R, Hehir-Kwa JY, Lelieveld SH, Castelein S, Gilissen C, de Wijs IJ, Admiraal RJ, et al. The diagnostic yield of whole-exome sequencing targeting a gene panel for hearing impairment in the Netherlands. Eur J Hum Genet. 2017;25(3):308-14.

49. Shearer AE, Kolbe DL, Azaiez H, Sloan CM, Frees KL, Weaver AE, Clark ET, Nishimura CJ, Black-Ziegelbein EA, Smith RJ. Copy number variants are a common cause of non-syndromic hearing loss. Genome Med. 2014;6(5):37.

50. Ji H, Lu J, Wang J, Li H, Lin X. Combined examination of sequence and copy number variations in human deafness genes improves diagnosis for cases of genetic deafness. BMC Ear Nose Throat Disord. 2014;14:9.

51. Likar T, Hasanhodzic M, Teran N, Maver A, Peterlin B, Writzl K. Diagnostic outcomes of exome sequencing in patients with syndromic or nonsyndromic hearing loss. PLoS One. 2018;13(1):e0188578.

52. Gasparini P, Rabionet R, Barbujani G, Melchionda S, Petersen M, Brondum-Nielsen K, Metspalu A, Oitmaa E, Pisano M, Fortina P, et al. High carrier frequency of the 35delG deafness mutation in European populations. Genetic analysis consortium of GJB2 35delG. Eur J Hum Genet. 2000;8(1):19-23.

53. Estivill X, Fortina P, Surrey S, Rabionet R, Melchionda S, D'Agruma L, Mansfield E, Rappaport E, Govea N, Mila M, et al. Connexin-26 mutations in sporadic and inherited sensorineural deafness. Lancet. 1998; 351(9100):394-8

54. Kenneson A, Van Naarden Braun K, Boyle C. GJB2 (connexin 26) variants and nonsyndromic sensorineural hearing loss: a HuGE review. Genet Med. 2002;4(4):258-74.

55. Wei X, Sun Y, Xie J, Shi Q, Qu N, Yang G, Cai J, Yang Y, Liang Y, Wang W, et al. Next-generation sequencing identifies a novel compound heterozygous mutation in MYO7A in a Chinese patient with usher syndrome 1B. Clin Chim Acta. 2012;413(23-24):1866-71.

56. Behar DM, Davidov B, Brownstein Z, Ben-Yosef T, Avraham KB, Shohat M. The many faces of sensorineural hearing loss: one founder and two novel mutations affecting one family of mixed Jewish ancestry. Genet Test Mol Biomarkers. 2014;18(2):123-6. 
57. Lu Y, Zhou X, Jin Z, Cheng J, Shen W, Ji F, Liu L, Zhang X, Zhang M, Cao Y, et al. Resolving the genetic heterogeneity of prelingual hearing loss within one family: performance comparison and application of two targeted next generation sequencing approaches. J Hum Genet. 2014;59(11):599-607.

58. Qing J, Yan D, Zhou Y, Liu Q, Wu W, Xiao Z, Liu Y, Liu J, Du L, Xie D, et al. Wholeexome sequencing to decipher the genetic heterogeneity of hearing loss in a Chinese family with deaf by deaf mating. PLoS One. 2014;9(10):e109178.

59. Boycott KM, Vanstone MR, Bulman DE, MacKenzie AE. Rare-disease genetics in the era of next-generation sequencing: discovery to translation. Nat Rev Genet. 2013;14(10):681-91.

60. Maxwell KN, Hart SN, Vijai J, Schrader KA, Slavin TP, Thomas T, Wubbenhorst B, Ravichandran V, Moore RM, Hu C, et al. Evaluation of ACMG-guidelinebased variant classification of Cancer susceptibility and non-Cancerassociated genes in families affected by breast Cancer. Am J Hum Genet. 2016;98(5):801-17.

61. Bademci G, Foster J 2nd, Mahdieh N, Bonyadi M, Duman D, Cengiz FB, Menendez I, Diaz-Horta O, Shirkavand A, Zeinali S, et al. Comprehensive analysis via exome sequencing uncovers genetic etiology in autosomal recessive nonsyndromic deafness in a large multiethnic cohort. Genet Med. 2016;18(4):364-71.

62. Kalia SS, Adelman K, Bale SJ, Chung WK, Eng C, Evans JP, Herman GE, Hufnagel SB, Klein TE, Korf BR, et al. Recommendations for reporting of secondary findings in clinical exome and genome sequencing, 2016 update (ACMG SF v2.0): a policy statement of the American College of Medical Genetics and Genomics. Genet Med. 2017;19(2):249-55.

63. Consugar MB, Navarro-Gomez D, Place EM, Bujakowska KM, Sousa ME, Fonseca-Kelly ZD, Taub DG, Janessian M, Wang DY, Au ED, et al. Panelbased genetic diagnostic testing for inherited eye diseases is highly accurate and reproducible, and more sensitive for variant detection, than exome sequencing. Genet Med. 2015;17(4):253-61.

64. Rehm HL. Disease-targeted sequencing: a cornerstone in the clinic. Nat Rev Genet. 2013;14(4):295-300.

Ready to submit your research? Choose BMC and benefit from:

- fast, convenient online submission

- thorough peer review by experienced researchers in your field

- rapid publication on acceptance

- support for research data, including large and complex data types

- gold Open Access which fosters wider collaboration and increased citations

- maximum visibility for your research: over $100 \mathrm{M}$ website views per year 